\title{
ENTRE MEMÓRIA E ATIVISMO POLÍTICO: CONTRIBUIÇÕES DE NAWAL EL SAADAWI PARA O FEMINISMO EGÍPCIO E TRANSNACIONAL
}

\author{
BETWEEN MEMORY AND POLITICAL ACTIVISM: \\ NAWAL EL SAADAWI'S CONTRIBUTIONS TO \\ EGYPTIAN AND TRANSNATIONAL FEMINISM
}

Flávia Abud Luz ${ }^{1}$

\begin{abstract}
Resenha comentada de "A Face oculta de Eva: as mulheres do mundo árabe" "A Mulher com olhos de fogo - o despertar feminista" (publicações brasileiras, de 2002 e de 2019, respectivamente).
\end{abstract}

\begin{abstract}
Resumo: A partir de reflexões das obras $A$ face oculta de Eva e A mulher com olhos de Fogo, da ativista egípcia Nawal El Saadawi e do desenvolvimento de discussões entre memória, trajetória e a busca das mulheres muçulmanas por direitos em Estados do Oriente Médio e Norte da África, esta resenha comentada visa apresentar as possibilidades e os desafios de problematizar a agência feminista com foco em questões como a normatização dos corpos femininos pelo viés da tradição e a discussão na intersecção entre gênero, cultura e religião que caracteriza a obra da autora.
\end{abstract}

Palavras-chave: Mulheres muçulmanas; Memória; Ativismo político.
Abstract: From reflections on works Hidden face of Eve (2002) and Women at Point Zero (2019) - both in Portuguese - of Egyptian activist Nawal El Saadawi and the development of discussions between memory, trajectory and the pursuit of muslim women for rights in Middle Eastern and North African states this commented review aims to present the possibilities and challenges of problematizing the feminist agency focusing on issues such as the normalizations of female bodies by tradition as well as the intersection between gender, culture and religion that is a feature of author's work.

Key-words: Muslim women; Memory, Political activism.

\section{INTRODUÇÃO}

As discussões acerca do status da mulher no Islã não são recentes dentro e fora do Islã e de países com populações muçulmanas, porém, sua expressão a nível internacional, observada principalmente durante a primeira década do século XXI com discursos acerca da necessidade de libertar mulheres muçulmanas no Afeganistão² ou com os debates acerca do uso do véu

\footnotetext{
1 Doutoranda em Ciências Humanas e Sociais pela Universidade Federal do ABC (UFABC), mestre em Ciências da Religião, especialista em Política e Relações Internacionais e graduada em Relações Internacionais. ORCID ID https://orcid.org/0000-0001-5979-3445. Link para o Currículo Lattes: http://lattes.cnpq. br/4539509603341152. Contato: flavia.abud.luz@hotmail.com.

2 Lila Abu-Lughod (2012, p. 451-455) discute em profundidade as contraditórias justificativas para a intervenção no Afeganistão que enfatizavam uma pretensa vontade de "libertar as mulheres de cobertura"
} 
em locais públicos de países europeus, como a França. A mulher e, sobretudo, seu corpo se configuram como um espaço de disputa de narrativas acerca do status e do papel da mulher nas sociedades muçulmanas que é ancorado na história e na memória, sendo estes elementos ressignificados por cada movimento contestatório (conservador ou de cunho crítico, como os movimentos feministas nacionais e o discurso feminista islâmico que pretende ser internacional).

0 resgate da história e memória do início da religião islâmica é um recurso frequentemente utilizado por lideranças de comunidades de cunho conservador para argumentar que o status da mulher no Islã é superior aquele que era observado no período pré-islâmico, e desta forma contrapor qualquer forma de discurso que busque a discussão ampliada de tal status, fato evidenciado principalmente entre o final do século XIX e início do século XX, ou seja, é possível falarmos que se configura um espaço de disputa de narrativas acerca do status e do papel da mulher nas sociedades muçulmanas que é ancorado na história e na memória, sendo esses elementos ressignificados por cada movimento contestatório (conservador ou de cunho crítico).

A construção de gênero presente na jurisprudência clássica (fiqh) e que foi mantida nas leis de família elaboradas na primeira metade do século XX tinha como característica central a desigualdade de gênero, principalmente no que diz respeito à compreensão dos direitos e deveres das mulheres e dos homens no casamento, visto que o casamento foi definido pelas diferentes escolas de pensamento jurídico, Maliki, Hanafi, Sharif (da corrente sunita do Islã) e Jafari (da corrente xiita), não estabelecendo obrigações recíprocas aos cônjuges. Tal construção foi alvo de questionamento por uma parcela de mulheres no mundo muçulmano e um discurso em contraponto às críticas (em sua maior parte desenvolvido por homens) articulou-se para lançar luz aos denominados "direitos das mulheres no Islã", com o intuito de apresentar alternativas (ou soluções) de base religiosa para acomodar as aspirações das mulheres relacionadas à igualdade, apresentando a noção de complementaridade ou equilíbrio dos direitos e deveres de homens e mulheres que contraem casamento. Sa'diyya Shaikh (2005, p. 147-162) explana o contexto em que alguns estudiosos muçulmanos reagiram de forma defensiva ao que consideravam um "ataque" ao Islã e reforçaram a noção de equidade ao argumentarem que a existência de direitos e deveres diferentes entre mulheres (e homens, sendo que o homem não é tratado aqui já que o objeto do texto são as mulheres) não significa desigualdade ou injustiça.

Para a crítica feminista nos países muçulmanos, de forma geral, é importante o resgate da memória e trajetória de vida de mulheres importantes no processo de fundação do Islã, tais como Khadija (a esposa de Maomé) e Fatima (filha de Maomé) para demonstrar a força das mesmas e sua atuação política junto à umma (comunidade holística dos muçulmanos) como algo natural neste período.

da situação opressiva em que viviam, bem como a utilização de explicações de cunho cultural (e religioso) ao invés de políticas ou históricas para lidar com a região, e analisa os sujeitos desses renovados discursos orientalistas, sobretudo as mulheres afegãs e sua ação política. 
Em A face oculta de Eva, livro originalmente escrito em árabe em 1977 e traduzido por Sherif Hetata (marido de Nawal El Saadawi) para o inglês na década de 1980, a médica psiquiatra, ativista feminista e autora egípcia Nawal El Saaadawi (2002, p.181-221) argumenta que a opressão das mulheres no Oriente Médio e Norte da África é um fenômeno de múltiplas forças e formas que interligam-se, como a estratificação social, a questão étnico-racial, a atuação da religião como força disciplinadora dos corpos e direitos das mulheres e, sobretudo, assume que as experiências femininas são complexas e diferenciam-se de acordo com as forças supracitadas. Quando se debruça sobre a sua sociedade de origem, El Saadawi (2002, p.25-72) aponta as feridas abertas e os vícios da mesma, busca utilizar de suas experiências pessoais e daquelas vivenciadas por colegas ou pacientes (de forma discreta para não expor-las) para transformar o sofrimento e a dor em um movimento de conscientização acerca de aspectos como a opressão patriarcal e seus efeitos na vida cotidiana das mulheres. Além disso, El Saadawi incentiva a autonomia econômica das mulheres e ressalta a importância do acesso à educação.

Em A Mulher com Olhos de Fogo: o despertar feminista (2019), El Saadawi (2019, p.19-27; 31-80) parte do testemunho verídico de Firdaus, uma prostituta condenada à pena de morte e cuja vida é permeada por uma série de situações que restringem suas escolhas: morte dos pais, os abusos do tio que era responsável por ela, a impossibilidade de continuar os estudos e a experiência insustentável de casar-se jovem com um homem mais velho e violento.

A agência de Firdaus desenvolveu-se paralelamente ao poder religioso e patriarcal que faziam com que ela sempre retornasse a estaca zero, ou seja, ela sempre buscava formas de reinventar seus sonhos e garantir sua sobrevivência em situações hostis a ela. Um momento de maior intensidade do movimento de despertar da consciência de Firdaus com relação à si mesma e com seu histórico conturbado de violências (como abuso infantil, violência doméstica quando casada e agressões físicas ocasionadas por sua profissão) ocorreu quando Firdaus descreve que percebeu que era melhor para ela ser prostituta e "escolher trabalhar para si" em vez de ser uma esposa cujo corpo detinha um status inferior pelo dever conjugal (de estar disponível ao marido e obedecê-lo). A redação de El Saadawi na língua árabe é considerada (pela própria autora) uma forma de resistência à opressão em suas diversas formas; indica que seu público-alvo é primeiramente de cunho regional e ao apresentar os problemas de sua sociedade e da região não se sugere interferência estrangeira para lidar com tais problemas/questões.

\section{TRAJETÓRIA DO MOVIMENTO FEMINISTA EGÍPCIO E 0 DESENVOLVIMENTO DA OBRA DE NAWAL EL SAADAWI}

Enquanto consciência da desigualdade de gênero e compreensão da privação de direitos (em amplo sentido, considerando direitos políticos, econômicos e aqueles relacionados ao 
domínio da religião sobre a política), por meio do código de status pessoal ou leis de família que trazem diferentes direitos e deveres para mulheres e homens, que em um contrato de casamento e o esforço das mulheres para reparar tal situação representou uma espécie de ameaça ao poder patriarcal estabelecido no Egito. Durante o fim do século XIX e início do $\mathrm{XX}$ a referida consciência ampliou-se, juntamente com o processo de modernização do país que ainda se encontrava sob o poder colonial britânico e buscava reivindicar os direitos de todos (da grande quantidade de camponeses até a elite que tivera acesso à educação) por meio da união de seus cidadãos em torno de um movimento nacionalista (Margot Badran, 2011: 79-80; Nabila Ramdani, 2013: 39-50).

Neste contexto, o nacionalismo e o feminismo se entrelaçaram em movimentos nacionalistas em que a presença feminina era forte, tendo em vista que o nacionalismo (em suas várias concepções, das conservadoras até aquelas mais à esquerda ou socialista no espectro político) foi observado como um veículo para as reivindicações pelos direitos das mulheres, tais como o acesso à educação. Porém, as diferenças étnicas e religiosas também detinham um peso importante no comportamento das mulheres egípcias e em suas atuações políticas. Nas últimas décadas do século XIX surgiram no Egito diversos jornais e revistas fundados e organizados por mulheres que traziam como conteúdo central mensagens de promoção da igualdade entre os gêneros (questionando assim o domínio patriarcal) e clamavam pela participação das mulheres na arena pública de um Estado livre do poderio colonial britânico.

Um feminismo secular centrado na formação e consolidação do Estado independente emergiu no século XX, sobretudo após a Primeira Guerra Mundial, sob a forma de movimentos sociais cuja religião também figurava como elemento de união. Mulheres cristãs e muçulmanas concordavam com a pauta da educação e da atuação no âmbito político e público, porém a religião tida nesta fase como elemento de âmbito privado ainda detinha o poder de determinar o código de status pessoal a ser adotado e, consequentemente, em que medida as demandas por igualdade de gênero no âmbito familiar, por exemplo, poderiam ser alcançada. Ainda em 1909, portanto antes da formação da União Feminista Egípcia (UFE) ${ }^{3}$, a egípcia Malak Hafini Nasif protestou contra abusos relacionados às leis de família (como o direito dos homens à poligamia e ao divórcio de forma unilateral, repudiando a mulher, por exemplo), clamou pelo direito das mulheres de participarem de orações nas mesquitas e desenvolverem estudos religiosos, argumentando que a segregação ou exclusão imposta às mulheres estaria em desacordo com os princípios do Islã (Badran, 2009: 17-32).

Os movimentos das mulheres egípcias serviram de exemplo positivo para a eclosão de outros movimentos em sociedades muçulmanas na região, contudo a trajetória dos direitos das mulheres foi marcada por avanços e retrocessos, sendo que entre tais extremos

\footnotetext{
${ }^{3}$ A União Feminista Egípcia é considerada o primeiro movimento feminista de alcance nacional no Egito, fundada em 1923 por Huda Sharawi. De acordo com Ramdani (2013, p. 40-42), estudos historiográficos mais recentes, como os desenvolvidos na década de 1980 por Margot Badran, apresentam que mulheres de diferentes classes sociais, principalmente as de classe média, envolveram-se na causa dos direitos das mulheres nas primeiras décadas do século XX.
} 
observou-se a garantia do direito de voto e de eleição para cargos públicos (em 1956) e a revogação, tempo mais tarde, no governo de Hosni Mubarak da alteração no código de status pessoal que permitia às mulheres de iniciarem um pedido de divórcio, sancionada em 1979 no governo de Anwar Sadat.

\title{
Nawal El Saadawi nasceu em 1931 em uma comunidade rural tradicional egípcia
} e a sua socialização era fruto de um contexto marcado pela hierarquização de gêneros proveniente dos costumes. Ainda quando criança, El Saadawi passou pela complexa e traumática experiência da mutilação genital feminina (MGF) ${ }^{4}$ (amputação do clitóris) e percebeu que entre suas colegas de escola tal prática prevalecia com relação aos corpos de meninas à época, independentemente da origem da família (rural ou urbana) ou classe social (alta, média ou baixa). El Saadawi descreve na primeira parte da obra A face oculta de Eva (2002) o momento em que a sua irmã mais nova é levada para a mesma experiência que ela acabara de enfrentar:

\begin{abstract}
Sua face era de uma palidez mortal e seus enormes olhos negros encontraram-se com os meus por uma fração de segundo. Era um olhar de profundo terror do qual jamais pude esquecer. Um instante depois ela desapareceu por trás da porta do banheiro onde eu acabara de estar. 0 olhar que trocamos parecia dizer: "Agora sabemos o que é isso. Agora conhecemos nossa tragédia. Nascemos com um sexo especial, o sexo feminino. Estamos predestinadas a provar o sabor da desgraça, e a ter uma parte de nosso corpo mutilada por mãos insensíveis, e cruéis." A minha família não era uma família egípcia sem cultura. Ao contrário, tanto meu pai quanto minha mãe tinham tido a sorte de receber uma boa educação, segundo os padrões daquela época. [...] Contudo, o costume de circuncidar as meninas prevalecia naquela época, e menina alguma poderia impedir que seu clitóris fosse amputado, independentemente do fato de sua família morar em zona rural ou urbana (El Saadawi, 2002: 27).
\end{abstract}

A mutilação genital feminina ${ }^{5}$, juntamente com a observação das distinções sociais que eram feitas entre meninas (e meninos) na sociedade (como da natureza das tarefas

\footnotetext{
${ }^{4} 0$ termo mutilação genital feminina (MGF) é utilizado ao longo desta resenha comentada como alternativa ao termo circuncisão feminina que foi empregado na edição brasileira do livro. A edição do livro é anterior ao debate internacional existente acerca da mutilação genital e ao usar o termo MGF pretendo uma aproximação das observações e reflexões de Nawal El Saadawi com o debate internacional em curso. A mutilação genital feminina, de acordo com a Declaração Conjunta (WHO; UNICEF; UNFPA, 1997 apud WHO, 2008: 4), "compreende procedimentos relacionados à remoção parcial ou total de órgãos genitais femininos externos ou lesões nos órgãos femininos sem necessidade médica" e é classificada em quatro tipos, que dizem respeito à remoção parcial/total do clitóris ou incisões na vulva.

${ }^{5} \mathrm{O}$ relatório "Female Genital Mutilation/Cutting: A statistical overview and exploration of the dynamics of change" da Unicef trouxe uma ampla análise de dados de duas décadas de pesquisas acerca da prevalência e tendência das práticas de mutilação genital feminina/cutting em 29 países na África e Oriente Médio. Em números totais se constatou que cerca de 125 milhões de mulheres e meninas passaram por alguma forma de mutilação (MGF ou cutting), sendo que no Egito, por exemplo, vive um número que corresponde a um quinto deste total. Outros dados sobre o Egito podem ser destacados, a saber: entre os anos de 1995 e 2008 ocorreu um aumento na porcentagem de meninas que passaram por alguma forma de MGF/cutting realizada por profissionais da saúde (médicos, enfermeiros) em detrimento dos praticantes tradicionais (dayas ou parteiras); ao mesmo tempo o país (juntamente com a Eritreia e o Sudão) instituiu campanhas com o objetivo de desencorajar a prática de mutilação e, no ano de 2007, uma fatwa (edito religioso) que condenou as práticas de mutilação, explicando que na lei islâmica (Shari'a) não há base para as mesmas (UNICEF, 2013: 22, 25-25, 46, 70-71, 109-110).
} 
realizadas por ambos, sendo que às meninas coubera aprender tarefas domésticas e estudar, quando as famílias assim permitissem, enquanto os meninos deviam dedicar-se apenas aos estudos) e até mesmo a constatação - a partir da vivência dos parentes mais distantes de que algumas das meninas ainda jovens tiveram que deixar a escola para serem expostas ao casamento ou eram subjugadas por seus irmãos, mesmo se fossem mais novos que elas, constituem aspectos fundamentais das discussões de El Saadawi acerca da disparidade entre os gêneros na sociedade egípcia (El Saadawi, 2002: 25-31).

El Saadawi (2002: 25-36; 41-48; 49-58; 2019: 32-42) compreende que os meninos/ homens também eram alcançados pela prática disciplinadora com relação aos corpos e o impedimento para expressar a sexualidade fora de um casamento, porém ela afirma que a segregação sexual imposta por uma moral rígida (que combinava elementos religiosos) atingia mais as meninas/mulheres que poderiam tornar-se alvo de investidas até mesmo de membros da família, como ocorreu, por exemplo, com Firdaus na infância, que foi alvo de abusos por parte do tio que já estava entrando na fase adulta. Neste contexto, ainda existe um agravante de que qualquer falta realizada por meninos/homens era vista com menos gravidade do que àquelas desempenhadas por meninas/mulheres, principalmente, se considerarmos que da honra da mesma (sua pureza e virgindade) também derivava, para a sociedade da época, a honra da família. Assim, El Saadawi destaca tal problemática, presente na sociedade:

\begin{abstract}
Muitas meninas expõem-se a incidentes do tipo. 0 elemento masculino pode ser seu irmão, primo, tio, avô ou até mesmo o pai. Caso não seja um membro da família, pode ser o guarda ou porteiro da casa, o professor, o filho do vizinho ou qualquer outro homem. Esses incidentes de violação sexual podem acontecer sem o uso de força. Se a garota for mais madura e resistir, o agressor ora recorre a um misto de ternura e sedução, ora à força física. Na maioria dos casos a garota cede e tem medo de fazer queixa a alguém porque, havendo alguma punição, esta acabará sendo imposta a ela. É somente a mulher quem perde a honra e a virgindade. 0 homem nunca perde nada, e o pior castigo que lhe pode acontecer (caso não seja membro na família) é ser obrigado a se casar com a garota (El Saadawi, 2002: 35).
\end{abstract}

Nawal El Saadawi passou parte de sua juventude e início da vida adulta refletindo sobre a posição da mulher na sociedade egípcia a partir de situações do cotidiano, questionando o porquê de certos costumes e práticas, tais como o cuidado exigido das meninas com relação aos seus movimentos quando fossem brincar; a dificuldade de jovens mulheres exercerem a sexualidade em sua plenitude devido à MGF, ou a expectativa de que as mulheres deveriam ser mais silenciosas e contidas em seus gestos e voz em público.

A questão da expressão da sexualidade, por exemplo, aparece com frequência na narrativa de Firdaus, em A Mulher com Olhos de Fogo: o despertar feminista (El Saadawi, 2019: 34-36, 44-46, 90-94), que questionava em diversos momentos o porquê ela não podia sentir prazer, mesmo nas poucas ocasiões em que se apaixonou durante a vida adulta, visto que a única experiência que ela recorda como prazerosa vinha de um momento da infância partilhado com um garoto (Mohammadain), mas tal sensação e recordação passaram a 
ser invadidas por experiências negativas como a circuncisão e as investidas de seu tio. Em determinado momento da narrativa, Firdaus descreve um episódio de estranhamento com relação às atitudes de seu tio e detalha o impacto delas para ela:

Ele estava fazendo comigo o que Mohammadain havia feito antes. Na verdade estava fazendo mais, mas eu agora não sentia aquela intensa sensação de prazer que irradiava de uma parte desconhecida e ainda assim familiar de meu corpo. Fechei os olhos e tentei encontrar o prazer que eu havia experimentado antes, mas em vão. Foi como se eu não conseguisse mais identificar o ponto exato de onde o prazer costumava emergir, ou como se uma parte de mim, do meu ser, tivesse partido para nunca mais voltar (Firdaus apud El Saadawi, 2019: 36).

Em outra passagem, agora Firdaus já adulta e atuando como prostituta na cidade do Cairo (sob a tutela da Senhora Sharifa), conversa com Sharifa justamente sobre suas experiências sexuais presentes e como ela entende que o prazer que tinha vivenciado na infância com Mohammadain não seria mais algo possível para ela, sendo que em seu lugar ficou apenas uma dor e um corpo que ela não mais reconhecia, mesmo sendo o seu:

Em algum lugar no meu corpo eu podia sentir bem vagamente um estranho estremecimento. A princípio parecia ser prazer, um prazer próximo da dor. E terminava como dor, uma dor que transmitia a sensação de prazer. Essa sensação pertencia a um passado distante, e de alguma maneira havia me acompanhado desde o início. Eu a havia experimentado muito tempo atrás, mas a acabei esquecendo com o tempo. De qualquer maneira, ela parecia remontar a um tempo ainda anterior à minha vida, a um momento anterior ao meu nascimento, como uma coisa que surgiu junto com uma ferida muito antiga, num órgão que já não era mais meu, no corpo de uma mulher que já não era mais eu (Firdaus apud El Saadawi, 2019: 91).

A oportunidade de seguir com os estudos e cursar a universidade de medicina, com especialização em psiquiatria (formando-se em 1955), permitiu a El Saadawi o contato com pacientes mulheres de outros países árabes e a constatação de que suas indagações também eram observadas em outras sociedades e que era preciso questionar as bases, sejam elas de origem religiosa, econômica, social ou política, que exerciam influência sobre a liberdade da mulher em amplo sentido. Tendo em vista uma série de tópicos que permeiam suas obras em questão, desde a circuncisão, o abuso de meninas, o casamento e o divórcio, El Saadawi explana assertivamente a interação entre elementos de ordem política e econômica que contribuem para a manutenção da opressão feminina, assim

as pessoas, com suas exigências de vida, constituem a força geradora, a diretriz que se traduz, na análise final, mediante determinação política, da diplomacia, enfim, pelo regime político do país. Essa vida individual obviamente engloba as complexidades do sexo, as relações entre um homem e uma mulher, e as relações de produção e divisão do trabalho. Aqueles que subestimam os problemas da mulher, e do sexo, ou desconhecem ou não compreendem os princípios da política. Não é mais possível ignorar o fato de que a condição desprivilegiada da mulher conduz indubitavelmente ao retrocesso de toda a sociedade. Por esse exato motivo, é necessário enxergar a emancipação feminina como elemento integrante da luta contra todas as formas de opressão, fazendo parte de tentativas de liberar todas as classes exploradas, tanto política como sexualmente (El Saadawi, 2002: 16). 
Nas décadas de 1970 e 1980 a experiência profissional ao lidar com pacientes e a experiência pessoal deram origem a uma série de artigos e livros que chamaram a atenção ao questionarem a normatização dos corpos femininos (seja pela MGF, ou seja, pela questão da honra da família relacionada à preservação, a todo custo, da virgindade da mulher) e ao clamarem pela autonomia das mulheres com relação aos seus corpos, seus recursos financeiros e suas alterações no código de status pessoal. El Saadawi desenvolveu uma carreira na saúde pública que era pautada pelo seu ativismo com relação à libertação das mulheres de todas as formas de opressão, discriminação e violência, chamando a atenção para sua pessoa, no Egito e região. Em 1981 El Saadawi foi presa, junto a outros críticos do governo de Anwar Sadat.

O período de cárcere, a proibição da circulação de sua obra no Egito e os cinco anos de exílio nos Estados Unidos não foram um impedimento para El Saadawi continuar fazendo suas críticas e reflexões. Ela ainda hoje se posiciona, sempre que possível, questiona os rumos dos movimentos de mulheres muçulmanas e as pautas reivindicativas destes movimentos, como a política do véu (que é constantemente retomada, inclusive por ativistas ocidentais). El Saadawi participou das manifestações populares na Praça Tahir, no Cairo, no que se convencionou denominar Primavera Árabe (2011).

\section{MEMÓRIA, HISTÓRIA E ATIVISMO POLÍTICO: APROXIMAÇõES ENTRE AS OBRAS DE NAWAL EL SAADAWI E AS DISCUSSÕES EM TORNO DA MEMÓRIA}

Em seu texto seminal Memória, esquecimento e silêncio (1989), Michael Pollak apresenta o reconhecimento do que denomina caráter potencialmente problemático da memória coletiva que, por meio de uma abordagem construtivista, lidaria com a compreensão de como e por meio de quem (como, por exemplo, por uma coletividade que visa desenvolver a ideia de história oficial de um Estado-nação) os fatos sociais atravessam um processo de formalização, em que passam a ser dotados de estabilidade e duração e forjavam a memória coletiva.

A referida memória coletiva possui como característica uma ação uniformizadora e opressora com relação à memória e às experiências individuais, porém a memória consolida-se como uma área de disputa que é atravessada por processos de negociação entre indivíduo e coletividade, sendo que as memórias subterrâneas de grupos minoritários ou marginalizados na narrativa oficial são passadas adiante por meio da história oral (entre membros de tais grupos) e tinham no silêncio uma forma de resistência que permitia aguardar por um melhor momento para aflorarem sem se sujeitarem a alguma forma de enquadramento dentro da história oficial (Pollak, 1989: 3-15).

Neste sentido é possível argumentar que antes mesmo da atuação de El Saadawi o Egito já tinha passado por um processo de disputa de memórias em que os movimentos de mulheres desenvolvidos no processo de transformações internas, sobretudo com a formação 
do Estado independente, reivindicavam a participação feminina na arena pública, o acesso à educação e a alteração no código de status pessoal que regia a vida dos muçulmanos. Porém, a força dos movimentos de mulheres foi cooptada e suas reivindicações deixadas em um porvir que não ocorreu. Pollak argumenta que considerando que o passado é atravessado por silêncios e silenciamentos, processos de negociação, tensão e disputa entre memória coletiva e individual o importante é justamente ressaltar que

[...] o problema que se coloca a longo prazo para as memórias clandestinas e inaudíveis é o de sua transmissão intacta até o dia em que elas possam aproveitar uma ocasião para invadir o espaço público e passar do não-dito à contestação e à reivindicação; o problema de toda memória oficial é o de sua credibilidade, de sua aceitação e também de sua organização (Pollak, 1989: 9).

Algumas ideias desenvolvidas pelas expoentes desses movimentos supramencionados, tais como a adoção da bandeira do reformismo islâmico por meio da livre interpretação das fontes sagradas (ijthad) e a pauta do acesso à educação formal e religiosa permaneceram sob memórias subterrâneas, retomadas novamente por outros movimentos como forma de resistência ao caráter opressor e uniformizador da memória coletiva que já deixara de lado o protagonismo das mulheres na luta anticolonial.

Apesar das limitações impostas às mulheres de classe média e da área rural, Nawal El Saadawi se destacou, principalmente entre 1970 e 1980, por ser capaz de romper com os mecanismos religiosos e de poder que impunham o silêncio aos indivíduos, sobretudo às mulheres e as suas experiências traumáticas, que funcionavam dentro do campo de negociação entre as memórias coletivas e as memórias individuais, processos estes descritos por Pollak (1989, p.3-9) como uma forma de encontrar pontos de contato entre tais memórias e reconstruí-las em bases comuns. No caso egípcio, por exemplo, poder-se-ia pensar no nacionalismo ou no uso do discurso religioso que resgate um tempo histórico específico por meio do qual a vida cotidiana dos muçulmanos deveria ser guiada.

El Saadawi apresenta aos seus leitores, sobretudo em seu livro A face oculta de Eva (2002), memórias pessoais e de outras mulheres que são carregadas de experiências negativas com relação a elementos que constituem uma moral rígida (moldada por elementos econômicos, sociais, culturais e, muitas vezes, apresentada como uma expressão religiosa) que afetam mulheres e homens de formas desiguais e expõe a normatização dos corpos femininos por meio de argumentos morais ou religiosos - como a circuncisão feminina e a criminalização do sexo fora do casamento - , aspectos importantes que a autora apresenta da seguinte forma:

A religião é, particularmente, uma arma constantemente usada pelas sociedades tradicionalistas para refrear, ou até extinguir os esforços dos pesquisadores. Tenho notado com absoluta clareza que a religião, atualmente, é frequentemente usada como instrumento nas mãos dos poderes político-econômicos, é uma instituição utilizada por aqueles que dominam, para aquietar os que são dominados. Ela serve, dessa forma, aos mesmos propósitos que os sistemas jurídicos, educacionais, políticos, e até mesmo psiquiátricos, usados para perpetuar a família 
patriarcal, a qual, por intermédio da opressão exercida sobre mulheres, crianças e escravos, originou-se historicamente, obteve reforço e se mantém. Assim, em qualquer sociedade, torna-se impossível separar a religião do sistema político-social, ou manter o sexo isolado da política. A trilogia composta pela política, religião e sexo é a mais sensível de todas as áreas de qualquer sociedade. Esta sensibilidade torna-se particularmente mais intensa nos países em desenvolvimento com um background rural, onde os relacionamentos caracteristicamente feudais predominam (El Saadawi, 2002: 19).

As memórias da jovem Firdaus acerca das diversas violações sexuais perpetradas pelo seu tio ou da violência doméstica pelo marido mais velho (Sheik Mahmoud), por exemplo, que foram apresentadas à El Saadawi (2019: 36-48; 72-66) e transcritas pela autora também podem ser entendidas sob o ponto de vista de Pierre Nora (1993: 9-13), principalmente ao tratar do trânsito entre memória e história (definindo os limites e diferenças entre ambas as categorias) e dos lugares de memória e seus aspectos material, simbólico e funcional. Neste caso, a valorização da tradição e sua observação no que tange ao controle do corpo das mulheres, por exemplo, pode ser visto como uma expressão de lugar de memória, pois une elementos de ordem material e simbólica - por meio da modéstia na vestimenta com o uso do véu que simbolizava a pertença à religião e a observação de seus costumes - , bem como o aspecto funcional, pois os rituais ligados à honra da família são evocados em diversos momentos, tais como aqueles antes e depois do casamento, quando da necessidade de provar a pureza/virgindade da mulher.

As reflexões de El Saadawi pressupõem o encontro de uma escuta atenta dos interlocutores e é importante para contrapor a noção de uma "história oficial" da mulher no Islã que fazia alusão ao período pré-islâmico como sendo estruturado pela ignorância (sobretudo com relação ao tratamento direcionado às mulheres e a questão da ocorrência do infanticídio de meninas), e busca demonstrar os direitos que às mulheres foram garantidos quando da institucionalização do Islã .

A tradição, entendida aqui de acordo com a perspectiva crítica de Talal Asad (1996: 381-386, 397-402; 2015: 166-169) como um conjunto de discursos que orientam quais são as formas corretas de interação entre os indivíduos e ao tomarem corpo (prática), ficam enraizadas na história, normatizam o presente com relação a uma concepção de passado que serão transmitidas no futuro. Essa interpretação é questionada por El Saadawi, pois compartilha da narrativa de compatibilização entre direitos das mulheres, igualdade de direitos entre os gêneros e a religião, sendo essa compatibilidade apresentada como uma alternativa.

A construção discursiva do denominado feminismo islâmico, um movimento transnacional, bem como em relação às narrativas dos feminismos seculares nos países árabes-muçulmanos, sobretudo, é influenciada pelas proposições e questionamentos de El Saadawi, por seus clamores com relação à libertação dos corpos femininos e por sua compreensão

${ }^{6}$ Leila Ahmed (1992: 41-63) faz uma análise das relações estabelecidas entre as diversas sociedades islâmicas, a opressão da mulher e os discursos histórico-religiosos envoltos em tal opressão. 
interseccional que chama a atenção para questões como classe e raça e para o que ela mesma denomina de complexa tríade entre política, religião e sexo, ou seja, visa expor as diversas forças que levam à opressão da mulher ao apontar as relações entre o sistema político que se utiliza do Islã (e uma interpretação feita por homens acerca dos princípios religiosos) de acordo com seus interesses de manutenção de poder.

Nas obras A face oculta de Eva (2002) e A Mulher com Olhos de Fogo: o despertar feminista (2019), a médica, ativista e literária Nawal El Saadawi apresenta imagens fortes e relevantes da mulher na sociedade egípcia; demonstra que a opressão imposta à mulher (de modo geral) vai além de uma explicação baseada apenas na religião (o Islã), mas principalmente na relação entre religião, economia e política com intuito de manutenção de poder.

A valorização da memória, experiência e trajetória de El Saadawi em sua defesa dos direitos das mulheres permitem observar como é possível o desenvolvimento de uma narrativa que permita às mulheres alterar os pratos da balança da tradição em prol de uma igualdade praticável e visível entre mulheres e homens, principalmente no âmbito das leis de família (ou códigos de status pessoal).

0 encontro com as obras de El Saadawi é essencial a todos que desejam compreender a verdadeira e complexa situação da mulher muçulmana, descolando-se então de leituras rasas acerca das diversas experiências das mulheres no Oriente Médio e Norte da África.

\section{REFERÊNCIAS}

ABU-LUGHOD, Lila. "As mulheres muçulmanas precisam realmente de salvação?: reflexões antropológicas sobre o relativismo cultural e seus outros". Revista Estudos Feministas, v. 20, n. 2, p. 451-470, maio, 2012.

AHMED, Leila. Women and gender in Islam: roots of a modern debate. New York \& London: Yale University Press, 1992.

ASAD, Talal. "The idea of an anthropology of Islam". Poznan Studies in the Philosophy of the Sciences and the Humanities, v. 48, p. 381-406, january, 1996.

ASAD, Talal. "Thinking about tradition, religion, and politics in Egypt today". Critical Inquiry, volume 42, issue 1, p. 166-214, autumn 2015.

BADRAN, Margot. Feminism in Islam. Secular and Religious Convergences. Oxford: Oneworld Oxford, 2009.

BADRAN, Margot. "From Islamic feminism to a Muslim holistic feminism". IDS Bulletin, v. 42, n. 1, p. 78-87, january, 2011.

EL SAADAWI, Nawal. A face oculta de Eva: as mulheres do Mundo Árabe. São Paulo: Global Editora, 2002.

EL SAADAWI, Nawal. A mulher com olhos de fogo: o despertar feminista. São Paulo: Faro Editorial, 2019. 
NORA, Pierre. Entre memória e história: a problemática dos lugares. Projeto História: Revista do Programa de Estudos Pós-Graduados de História, vol.10, p. 7-28, julho-dezembro, 1993.

POLLAK, Michael. Memória, esquecimento, silêncio. Revista Estudos Históricos, vol. 2, no3 (janeiro-junho), p. 3-15, 1989.

RAMDANI, Nabila. Women in the 1919 Egyptian Revolution: from feminist awakening to nationalist political activism. Journal of International Women's Studies, v. 14, n. 2, p. 39-52, march, 2013.

SHAIKH, Sa'diyya. Transforming Feminism: Islam, women and gender justice. In: SAFI, Omid(ed). Progressive Muslims: on justice, gender and pluralism. London: Oneworld Oxford, 2005,p.147-162.

UNITED NATIONS CHILDREN'S FUND (UNICEF). Female Genital Mutilation/Cutting: A statistical overview and exploration of the dynamics of change. New York: UNICEF, 2013. Disponível em: <https://www.unicef.org/publications/index 69875.html>. Acesso em: 21 maio 2020.

WORLD HEALTH ORGANIZATION et al.. Eliminating Female Genital Mutilation: An interagency statement, UNAIDS,

UNDP,UNECA,UNESCO,UNFPA,UNHCHR,UNHCR,UNICEF,UNIFEM,WHO. Geneva: WHO, 2008. Disponível em: < https://www.who.int/reproductivehealth/publications/ fgm/9789241596442/en/>. Acesso em: 21/05/2020. 